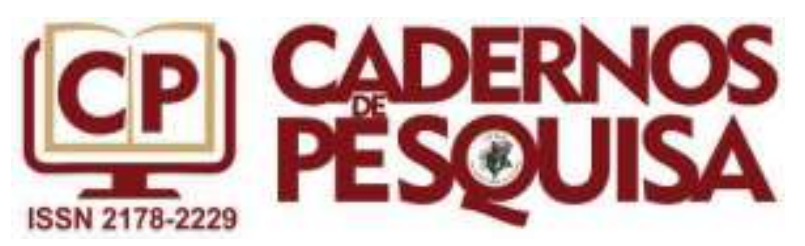

\title{
FORMAÇÃO CONTINUADA NA ESCOLA DE TEMPO INTEGRAL: CAMINHO PARA A PRÁTICA COLABORATIVA NO ENSINO MÉDIO
}

\author{
CONTINUOUS LEARNING IN FULL-TIME EDUCATION: A PATH \\ TO COLLABORATIVE PRACTICE IN HIGH SCHOOL
}

\author{
FORMACIÓN CONTINUADA EN LA ESCUELA DE TIEMPO \\ INTEGRAL: CAMINO HACIA LA PRÁCTICA COLABORATIVA EN \\ LA ENSEÑANZA MEDIA
}

Marcoelis Pessoa de Carvalho Moura ${ }^{1}$

ORCID: https://orcid.org/0000-0001-5123-5641

Maria da Glória Carvalho Moura²

ORCID: https://orcid.org/0000-0002-3686-9133

\begin{abstract}
Resumo: O presente artigo resulta de uma pesquisa sobre a formação continuada de professores nas escolas de Ensino Médio de Tempo Integral da Rede Pública Estadual de Educação do Piauí. Vinculada à Linha de Pesquisa: Formação Docente e Prática Educativa, do Programa de Pós-graduação em Educação e ao Núcleo Interdisciplinar de Pesquisa em Práticas Curriculares e Formação de Profissionais da Educação (NIPPC), da Universidade Federal do Piauí. Objetiva-se refletir sobre as implicações da formação continuada na escola para o exercício da prática docente. Para a produção deste estudo, foram utilizados dados obtidos através de entrevistas, da qual participaram 15 professores colaboradores. A análise, centrou-se em aspectos do desenvolvimento profissional destes sujeitos como resultante de processos de (auto)formação continuada após o início do exercício da atividade laboral na escola. Utilizou-se Metodologia Qualitativa do tipo Estudo de Caso com base, sobretudo, nos estudos de Yin (2010). Os resultados evidenciam as concepções dos colaboradores sobre o trabalho desenvolvido, com a descrição de estratégias utilizadas no cotidiano escolar. Concluiu-se que a formação continuada na escola é uma necessidade em meio a uma realidade permeada por mudanças. Diante deste cenário, ela representa tanto a oportunidade de conhecer perspectivas e experiências diferentes, quanto de novos conhecimentos. Esta formação, para ser significativa, deve estabelecer sempre o diálogo entre teoria e prática.
\end{abstract}

Palavras-chave: Escola de Tempo Integral. Ensino Médio. Formação Continuada. Práticas Pedagógicas. Desenvolvimento Profissional. Profissionalidade Docente

1 Universidade Estadual do Piauí - UESPI, Piauí, Brasil

2 Universidade Federal do Piauí - UFPI, Piauí, Brasil 
Abstract: This article is the result of a research on the continuous education of teachers in full-time public high schools in the state of Piauí. The study is linked to the Research Line: Teacher Training and Educational Practice, from the Postgraduate Program in Education, and the Interdisciplinary Research Center of Curriculum Practices and Training of Education Professionals (NIPPC), of the Federal University of Piauí. The purpose of this study is to reflect on the implications of continuous education at school for teaching practice. Data obtained from interviews with 15 collaborating teachers were used for the production of this study. The analysis focused on aspects of the professional development of these subjects as a result of continuous (self) training processes after they started working at these schools. A Qualitative Case Study Methodology was used, based mainly on the studies of Yin (2010). The results show the conceptions of the school staff on the work developed, with the description of strategies used in everyday school life. The study concluded that continuous education at school is a necessity in the midst of a reality marked by changes. In this scenario, it represents both the opportunity to get to know different perspectives and experiences, and to gain new knowledge. That for this training to be meaningful, it must always establish a connection between theory and practice.

Keywords: Full-Time School. High School. Continuous Education. Pedagogical Practices. Professional Development. Teacher Professionalism.

Resumen: El presente artículo es el resultado de una investigación sobre la formación continuada de los profesores en las escuelas de Enseñanza Media de Tiempo Integral de la Red Pública Estatal del Estado de Piauí. Vinculada a la Línea de Pesquisa: Formación Docente y Práctica Educativa, del Programa de Posgrado en Educación y al Núcleo Interdisciplinar de Pesquisa en Prácticas Curriculares y Formación de Profesionales de la Educación (NIPPC), de la Universidad Federal de Piauí. El objetivo es reflexionar sobre las implicaciones de la formación continuada en la escuela para el ejercício de la práctica docente. Para la elaboración de este estudio, se utilizaron datos obtenidos a través de entrevistas, en las que participaron 15 profesores colaboradores, el análisis, se centró en aspectos del desarrollo profesional de estos sujetos como resultados de procesos de (auto) formación continuada tras el inicio del ejercicio de la actividad laboral en la escuela. Se utilizó una Metodología Cualitativa del tipo Estudio de Caso con Base, en los estudios de Yin (2010). Los resultados evidencian las concepciones de los colaboradores sobre el trabajo desarrollado, con la descripción de las estrategias utilizadas en la rutina escolar. Se concluyó que la formación continuada en la escuela es una necesidad en medio de una realidad impregnada de cambios. Ante este escenario, representa tanto la oportunidad de conocer perspectivas y experiencias distintas, cuanto de nuevos conocimientos. Esta formación, para ser significativa, debe siempre establecer el diálogo entre teoría y práctica.

Palabras clave: Escuela de Tiempo Integral. Enseñanza Media. Formación Continuada. Prácticas Pedagógicas. Desarrollo Profesional. Profesionalidad Docente.

\section{INTRODUÇÃO: CONTEXTO E CAMINHOS DA PESQUISA}

As escolas de tempo integral são uma realidade em todo o país e seu funcionamento tem sido feito de forma diferenciada atendendo os critérios do sistema ou rede de ensino. No Ministério da Educação (MEC), no ano de 2009, foi criado o Programa Ensino Médio Inovador (ProEMI), responsável por induzir a ampliação da jornada escolar, no sentido da reformulação curricular voltada para uma de formação integral do estudante, perspectiva em pauta nas discussões para as Diretrizes Curriculares Nacionais do Ensino Médio (DCNEM) aprovadas pelo Conselho Nacional de Educação (CNE) no ano de 2012. 
O referido programa foi gestado na Coordenação Geral de Ensino Médio, da Secretaria da Educação Básica do Ministério da Educação (SEB/MEC), que estabeleceu parceria com as Secretarias de Educação dos Estados da Federação através do Fórum de Coordenadores do Ensino Médio. Nesse mesmo período as secretarias de Estado de Educação implantavam escolas de tempo integral com oferta de ensino médio.

No caso das escolas da Rede de Estadual de Ensino do Estado do Piauí, lócus da pesquisa que deu origem a este trabalho, as escolas de tempo integral foram instituídas pelo Decreto $n^{\circ} 13.457 / 2008^{3}$ (PIAUÍ, 2018) com o funcionamento a partir do ano de 2009 das primeiras 14 escolas $^{4}$ com oferta de Ensino Fundamental e Médio (modalidades regular e profissional).

No Piauí o funcionamento das escolas de ensino médio de tempo integral, ganhou impulso com os recursos do Programa Ensino Médio Inovador que por meio do Programa Dinheiro Direto na Escola (PDDE), injetava recursos para a realização de atividades pedagógicas com a finalidade de renovação curricular e formação continuada de professores.

No Ano de 2014 a maioria das escolas da Rede Estadual do Piauí, entre as quais as de tempo integral, firmaram parceria em torno do Pacto pelo Fortalecimento do Ensino Médio ${ }^{5}$ e nestas escolas foi realizado um curso de formação de professores e coordenadores pedagógicos, coordenado no Estado pela Universidade Federal do Piauí em parceria com a Universidade Estadual do Piauí e Secretaria de Estado do Piauí.

Nesse período a Rede Pública Estadual contava com 34 escolas de Ensino Médio funcionando em regime de tempo integral, sendo que destas, 29 como formação propedêutica, o que evidencia um contexto desafiador para a formação continuada de professores nas escolas de tempo integral de ensino médio realizado logo após encerrada a formação do Pacto pelo Fortalecimento do Ensino Médio, uma das primeiras iniciativas, senão a primeira, de formação mais sistemática realizada nestas escolas, voltada para discussão de questões pedagógicas e de concepções relacionadas à educação, ao ensino médio, juventude(s), áreas de conhecimento e trabalho interdisciplinar.

3 Decreto de18 de dezembro de 2008 - "Institui no âmbito da Secretaria de Educação e Cultura, os Centros Estaduais de Tempo Integral, e dá outras providências" - além da ementa, está organizado em 11 artigos que orientam a organização e o funcionamento das escolas, com destaque para o objetivo geral e específicos; composição do corpo docente e discente; competências do Estado, entre as quais a gratificação por condição especial de trabalho.

4 Parnaíba (01 escola): Polivalente Lima Rebelo - Ensino Médio; Teresina (08 escolas) - João Henrique de Almeida Sousa - Ensino Médio; Pequena Rubim - Ensino Fundamental; Prof. Darcy Araújo - Ensino Fundamental; Milton Aguiar - Ensino Fundamental; Pe. Joaquim Nonato - Ensino Fundamental; Raldir Cavalcante Bastos - Ensino Fundamental; Duque de Caxias - Ensino Fundamental; Gov. Dirceu Mendes Arcoverde Educação Profissional; Campo Maior (01 escola): Cândido Borges - Educação Profissional; Regeneração (01 escola): Aurora Barbosa - Educação Profissional; Oeiras (01 escola): Des. Pedro Sá - Ensino Médio; São Raimundo Nonato (01 escola): Moderna - Ensino Médio; Guaribas (01 escola): Paulo Freire - Ensino Médio.

5 Programa de Formação Continuada, instituído no âmbito do MEC, voltado para professores e coordenadores de escolas de ensino médio das Redes Públicas. 
O presente texto objetiva refletir sobre as implicações da formação continuada na escola para o exercício da prática docente. Para tanto, trilhamos o caminho da pesquisa qualitativa do tipo Estudo de Caso, com base principalmente em Yin (2010), por se tratar de uma investigação centrada em seus sujeitos e nas múltiplas relações que estabelecem.

A opção por este tipo de pesquisa se justifica porque no âmbito da escola de tempo integral, em função da expansão do tempo-escola, a natureza dos processos de formação e das dinâmicas que constituem as relações internas são ativas, afetivas, dialogadas, o que interfere nas práticas e concepções de educação de toda a comunidade escolar.

Neste contexto, múltiplo e ao mesmo tempo dinâmico, houve a necessidade de uma metodologia de pesquisa capaz de investigar em profundidade o contexto real (Yin, 2010). Por isso, fizemos o recorte das escolas de tempo integral com oferta de ensino médio implantadas no ano de 2009, que totalizavam 05 (cinco) e destas, localizadas em regiões distintas do Estado, realizamos a investigação em 03 (três) no ano de 2015.

As escolas foram selecionadas pela participação em duas ações do Ministério da Educação, a primeira voltada para a revisão curricular e a segunda para a formação continuada, realizadas em parceria com a SEDUC/PI. A opção se deu por conta de as duas ações implicarem desenvolvimento de atividades formativas nas escolas.

A referida seleção permitiu assegurar elementos básicos comuns relevantes para o sucesso da investigação, tais como: período de funcionamento da escola no formato/ modelo de tempo integral, experiência dos professores com o modelo de tempo integral e participação docente em atividades de autoformação continuada na escola.

Com este último aspecto, central em nossa pesquisa, buscamos garantir que os colaboradores da pesquisa, tivessem participado de ações de formação, proporcionados por dois programas do MEC, por isso a importância dada ao tempo de permanência dos professores na escola. Com isto, os convidados preferenciais para participarem foram aqueles docentes que tivessem mais tempo de atuação na escola e tivemos colaboração de 15 professores.

De modo a garantirmos o sigilo de suas identidades, atendendo às normas do Conselho Nacional de Saúde, os colaboradores utilizam pseudônimos e para a escolha sugerimos nomes de instrumentos musicais ${ }^{6}$, para fazermos analogia à necessária sintonia destes para que a música seja harmoniosa, com o diálogo entre os professores, para que haja o mesmo efeito em relação à atividade pedagógica na escola.

Os professores escolheram seus pseudônimos. Entretanto, destacamos que um deles foi substituído, pois percebemos na produção deste, que o nome do instrumento musical, pode remeter diretamente à condição física de deficiência e temos por objetivo evitar a indução de interpretação equivocada. Esclarecemos outrossim, que optamos por não

6 - Pseudônimos escolhidos: Agogô, Bandolin, Bateria, Cavaquinho, Concertina, Harpa, Órgão, Saxofone, Tambor, Timbal, Trombone Trompa, Trompete, Tuba, Violão 
identificar o gênero dos participantes neste trabalho, de modo a não levar o(a) leitor(a) a vincular o discurso ao gênero do(a) colaborador(a).

Os dados obtidos por meio de entrevistas foram organizados em categorias, embora apenas duas sejam utilizadas para análise: "Formação em todas as suas dimensões: horários de aulas e estudos" e "Formação: reflexões teóricas, prática pedagógica aprendizagem", em outras palavras, os resultados trazidos para a reflexão no presente artigo configuram uma parte do que foi obtido em pesquisa mais ampla, que abrangeu, inclusive, outros instrumentos de pesquisa.

No decorrer da investigação e a partir do resgate do referencial teórico adotado, fizemos a correspondência categorias identificadas no discurso do(a)s participantes da pesquisa pelo método da Análise de Discurso que agrega aspectos social, humano e político (ORLANDI, 1988, 2012) aos processos ensino e aprendizagem e às relações que permeiam a prática pedagógica.

Estruturamos este estudo em quatro em seções. Na primeira apresentamos esta contextualização do nosso objeto de estudo, objetivos, metodologia; na segunda, fazemos um o resgate do referencial teórico sobre a relação entre prática pedagógica e identidade profissional, com foco na experiência dos professores; na terceira, apresentamos os resultados da pesquisa relativos à primeira categoria analisada, que envolve a identificação do lócus da pesquisa, importante para a compreensão do contexto de formação; na quarta seção, discorremos sobre a categoria que trata de formação continuada e profissionalidade docente, eixo central da pesquisa; por fim, na última seção - Conclusão, tecemos nossas considerações sobre as implicações da formação continuada para o desenvolvimento profissional do professor.

\section{EXPERIÊNCIA E COLABORAÇÃO: IDENTIDADE PROFISSIONAL E PRÁTICA PEDAGÓGICA NA DOCÊNCIA DE ENSINO MÉDIO}

A experiência do(a) professor(a) é sempre fonte de revisão da(s) teoria(s) que permeia $(m)$ sua prática, nesse sentido, oportuniza sua significação e a autoformação. A autorreflexão faz parte da prática do(a) professor(a) que conduz ao aperfeiçoamento de conhecimentos e qualifica suas competências e, ao mesmo tempo é formação continuada (NÓVOA, 2004).

Com isto, a prática pedagógica refletida a partir da experiência é compreendida como formação continuada e autoformação, mediadora de conhecimentos pedagógicos no processo de consolidação da profissionalidade docente, ou em outras palavras, é prática pedagógica em processo permanente de reflexão.

Para refletir melhor sobre a prática pedagógica, nos reportamos a Imbernón (2016) ao considerar que esta ação é trabalho árduo e, que, embora, para o imaginário social pareça simples, que não requer maiores habilidades, é de fato, atividade complexa e que está 
em constante transformação em face às mudanças cada vez mais aceleradas que ocorrem nos diferentes campos do conhecimento, da tecnologia e das relações interpessoais.

Com isto, a formação continuada busca satisfazer necessidades do (a)s professore (a)s em dois campos: o de atualização dos conhecimentos de sua área de formação específica e o do modo como ensinar melhor, sendo, em ambos, decisiva para o fortalecimento da identidade profissional do professor.

Esta concepção sobre a prática pedagógica é construída à luz do pensamento complexo sob o qual a fragmentação do conhecimento é responsável por produzir o que Morin (2015) nomeia de pensamento mutilado, condutor de ações mutilantes, que levam o professor à condição de isolamento profissional.

É nesse sentido que depreendemos a necessidade da formação continuada na escola por ser "[...] capaz de integrar os movimentos que o professor faz consigo mesmo e com os outros [...]" (ROCHA; ARRUDA; ANDRADE, 2018, 96), num processo de discussão de questões que vão de "pequenas" dificuldades relatadas por um ou alguns professores à troca de experiências e experimentos, que possam resultar em projetos pedagógicos interdisciplinares.

No entanto, mesmo em pleno século $\mathrm{XXI}$, o isolacionismo na escola é ainda forte e diz respeito a quatro aspectos: apresentação de uma realidade complexa como simples, o que denomina pensamento reducionista; objetividade imposta pelo sistema binário que impõe a condição do erro, na oposição verdadeiro-falso; pensamento linear que não permite pensar a partir de conexões entre fenômenos multidimensionais; maniqueísmo que impossibilita encontrar conexões entre pensamentos distintos, reforçando a ideia do erro, associado ao mal (MORIN, 2015).

Os aspectos elencados representam os pontos a serem superados no ideário pedagógico considerado conservador, bem como apontam o caminho a ser seguido pelo(a) professor(a), com o reconhecimento das conexões entre as áreas de conhecimento e dos componentes curriculares entre si.

Nesse sentido retornemos a Imbernón (2016) que, ao considerar as mudanças ocorridas nos séculos $X X$ e $X X I$, afirma que estas se refletem na profissão docente quando saímos do trabalho isolado, próprio do início do século $X X$, para compormos uma equipe de professores característica do final do século $\mathrm{XX}$ e do século $\mathrm{XXI}$, que altera os modelos relacionais, exigindo participação.

Então, saímos de uma sociedade que formava para o isolamento, característica do século $X I X$ e a maior parte do século $X X$, que se fez presente na escola, e no final do século $\mathrm{XX}$ e início do século XXI, temos uma escola com um coletivo que precisa aprender a trabalhar coletivamente, não como indivíduos com suas disciplinas nas escolas. Num contexto que Nóvoa (2019) denomina de processo de metamorfose, o que implica necessariamente na formação de professores. 
Atualmente professores formam uma equipe, mesmo no ensino médio, onde pode parecer que trabalham isoladamente. Por isto, "[...] durante o século XXI passou-se a uma reflexão além dos aspectos puramente técnicos e 'objetivos' que predominaram durante quase todo o século passado" (IMBERNÓN, 2016, p. 52), a processos subjetivos, que envolvem além do cognitivo, o afetivo e as dimensões socioculturais e históricas, atividades de integração.

Assim, nas relações entre professores no ambiente escolar, a escola na atualidade exige mais que o domínio do conteúdo a ser ensinado, pois a formação integral do educando requer que a prática pedagógica seja dialógica, sobretudo, numa escola em que a jornada é de 9 horas, ou de tempo integral, em que professores permanecem, por mais tempo em atividades pedagógicas e em contato com os mesmos estudantes, fator que influencia positivamente o desenvolvimento de maior vínculo pessoal.

Neste sentido, a teoria da complexidade se faz presente, uma vez que ela tem como base princípios que colocam no centro da atividade escolar o educando como sujeito de sua ação e que está em processo de construção do seu conhecimento, o que Morin (2011) descreve como ensinar a condição humana, na religação dos conhecimentos, possível apenas pelo diálogo com os professores, o que requer reflexão continua no processo de desenvolvimento profissional que se faz na escola.

A reflexão mediada pelo diálogo com o outro proporciona a construção de uma prática solidária e colaborativa necessária nas escolas de tempo integral, de acordo com Decreto-PI $n^{0} 13.457 / 2008$ que em seu art. $3^{\circ}$ determina entre os objetivos específicos: "I - estimular o desenvolvimento de estratégias educacionais voltadas para a questão do protagonismo infanto-junvenil; II - estimular formação continuada de professores e demais servidores [...]" (PIAUÍ, 2008).

O referido Decreto, foi atualizado e transformado em Lei no ano de 2018 sob o $\mathrm{n}^{\circ}$ 7.113/2018 e manteve a ementa e os objetivos do Decreto supracitado. Os objetivos se integram no sentido de proporcionar a reflexão sobre a proposta de formação do educando, que permeia uma escola que atende ao estudante em uma jornada que é praticamente o dobro do tempo em que atende o estudante que frequenta uma escola de tempo parcial.

Implica também a reflexão sobre a formação continuada dos professores, especialmente, como espaço de mudança de concepções, relações e práticas que porventura precisem ser mudadas, a exemplo da superação da ideia do erro como oposição ao acerto, mas como processo da construção do pensamento (MORIN, 2015).

Temos então, como exigência dos tempos atuais, uma alteração da cultura escolar pelas inovações na ciência, na tecnologia, nas escolas. E, com isto, no saber escolar e nas práticas pedagógicas. A compreensão da condição de juventude foi tema abordado em formação nas escolas pesquisadas, de modo a colocar em pauta, para a reflexão de professore(a)s, questões que envolvem a origem de conflitos intergeracionais e a própria condição de ser jovem na escola de ensino médio. 
Nesse sentido e, conforme pontuam Imbernón (2016) e Morin (2011, 2015), a profissão docente enfrenta desafios próprios da complexidade que a atualidade apresenta e implica não apenas o cuidado com a técnica e com o conhecimento a ser ensinado, mas também com outras dimensões básicas na formação e postura em frente à sua demanda de trabalho, entre as quais as relações socioafetivas e éticas.

A multidimensionalidade que caracteriza o processo de ensino-aprendizagem, a partir das inovações científico-tecnológicas, mostra que "[...] a missão e as respostas que atualmente se atribui e se exigem da escola estão, elas próprias, em profunda transformação, nem sempre como consequência destas heranças e debates" (ALCOFORADO, 2014, p 67), mas das múltiplas dimensões e das conexões com diferentes fenômenos que alteram as relações na escola e o conhecimento.

É neste contexto que as políticas produzidas no âmbito dos sistemas de ensino, alteram as relações e implicam mudanças de concepções e de práticas nas escolas, a exemplo das escolas do ensino médio, lócus da pesquisa que deu origem a este texto, que migraram do regime de tempo parcial para tempo integral, por uma decisão da Secretaria de Estado da Educação, por Decreto governamental, o que implicou mudanças de práticas, revisão de conceitos e aceitação do novo.

Em seguida, no final de 2009 as escolas pesquisadas passaram a integrar o Programa Ensino Médio Inovador (ProEMI), do Ministério da Educação, que também implicou em mudanças com vistas à revisão curricular "[...] sinalizado no Parecer do CNE como uma possível referência para a atualização das Diretrizes Curriculares Nacionais para o Ensino Médio" (SILVA, 2016, p. 93).

As mudanças assinaladas mostram a necessidade de formação continuada, o que era previsto, tanto em relação ao programa local (escolas de tempo integral), quanto ao programa do Ministério da Educação que na primeira versão do Documento Orientador/2009, trouxe em suas linhas de ação no item 8.3.3 "Melhoria das Condições de Trabalho Docente e Formação Continuada" (MINISTÉRIO DA EDUCAÇÃO, 2009, p.18).

A formação continuada como meio que viabiliza mudanças de acordo com o que planeja o Estado ou os governos, também é instrumento de reflexão individual e coletiva do professorado, em face às transformações inevitáveis que mudam o (a) próprio (a) professor (a), reconhecidamente ser inacabado, pela sua condição de humano (FREIRE, 2019). Este inacabamento resulta das mudanças que ele mesmo promove, (re)fazendo cultura, educação, trabalho, tecnologia, sua humanidade.

Nesse sentido, a formação continuada com vistas ao desenvolvimento profissional se faz pela análise e reflexão crítica sobre a prática, fazendo dela práxis, que tem "[...] a obrigação de construir ambientes favoráveis e o crédito que a partir de motivações intrínsecas, as pessoas têm dentro de si próprias tudo o que é necessário para empreender as mudanças necessárias [...] (ALCOFORADO, 2014, p. 77). 
As motivações intrínsecas, são aquelas que instigam os professores a aprender novos conhecimentos e a aperfeiçoá-los de modo a encontrar a satisfação no processo e com o resultado de sua prática. O contexto de mudanças conceituais, comportamentais e na estrutura do que estamos acostumados a lidar, requer a disposição para enfrentar o novo.

No contexto educacional do século XXI e a partir do ano de 2020, a profissão docente passa pela emergência de se adaptar abruptamente a recursos tecnológicos que proporcionam as atividades pedagógicas à distância, com as necessidades das aulas remotas, materiais didáticos e atividades escolares em plataformas digitais, em um processo acelerado de autoformação para atender novas demandas.

Muito embora os recursos tecnológicos já fizessem parte da vida da maioria dos professores e de boa parte dos estudantes do ensino médio, o uso pedagógico exigiu muito além das habilidades usuais do dia a dia, sobretudo do professorado. Exigiu o uso de recursos multimodais, outra postura, nova forma de entonação da voz, aquisição de novo vocabulário, gravação das aulas etc.

A necessidade de reinvenção da prática pedagógica e docente, inclusive a atenção em relação às questões éticas, envolvem tanto a liberdade de expressão, como atenção e respeito ao outro, quanto a difusão e obtenção de informações confiáveis contra o falseamento e manipulação da informação que circula nas redes sociais e no ambiente ciberespacial de um modo geral. O que se evidencia ao se verificar que,

Todo computador singular constitui uma estrutura hologramática que contém, potencialmente (virtualmente) toda a informação da internet. Não somente a parte se encontra no todo como o todo se encontra (virtualmente) nas partes. $O$ todo constitui uma rede em permanente expansão que cada novo elemento transforma e enriquece; constituído de inumeráveis circuitos recursivos, ao se enriquecer e se transformar, esse sistema se autorreproduz. (MORIN, 2015, p. 208).

Esta autorreprodução não é cópia do que já existe, mas algo novo que se amplia e renova em um processo de expansão. Neste contexto, o diálogo entre professores, gestores e estudantes se faz ainda mais necessário, pois além das questões éticas, temos outro desafio relacionado ao acesso às tecnologias de comunicação, uma vez que para a maioria dos estudantes do ensino médio o acesso é limitado e, ainda há um percentual significativo que não tem acesso a nenhum recurso que possibilite a adesão ao sistema remoto.

Segundo dados do Comitê Gestor da Internet no Brasil (CGI.br), relativos ao ano de 2017 a estimativa era de "[..] que 85\% da população entre 9 e 17 anos era usuária de Internet no país e a proporção desses usuários que acessou a rede por meio de dispositivo celular foi de 93\%" (REIS; DAYRELL, 2020, p.13).

Estes dados mostram o avanço da tecnologia entre crianças e adolescentes que formam a maioria da demanda do ensino fundamental anos finais e ensino médio. Porém, fica evidente que a tecnologia não estava universalizada e nem está, uma vez que as redes 
públicas de ensino no período da pandemia, e com o início das atividades remotas no ano de 2020 precisaram fornecer material impresso a muitos estudantes.

Assim, se por um lado, a internet possibilita ampliar horizontes daqueles que a ela tem acesso, e os dados mostram que, cada vez mais cedo as crianças estabelecem comunicação para além de seu espaço geográfico, o que demonstra sua familiaridade com os recursos tecnológicos, sobretudo, em situações de lazer, por outro, requer cautela para não gerar exclusões e deseducação, para as quais devemos considerar as questões técnicas, socioafetivas, éticas e de conhecimento.

Vale ressaltar que nos últimos dois anos as aulas remotas têm sido o principal recurso utilizado para garantir a escolarização formal exigindo dos professores não só a revisão das estratégias de ensino, mas a aquisição de novas habilidades, entre as quais o de desenvolvermos a multiliteracia que "[...] requer de nós professores-aprendizes, a maioria imigrantes no território virtual, maior cuidado e também compreensão das novas aprendizagens a serem adquiridas em um processo permanente de busca por novos conhecimentos" (MOURA; MOURA, 2021, p. 153).

Neste processo é que a inovação se faz presente, com a reinvenção de práticas, até porque o trabalho do professor do ensino médio é a mediação do saber com jovens e para estes o uso da internet é habitual em todos os espaços de convivência (REIS; DAYRELL, 2020).

Com isto, temos evidente que as mudanças na cultura escolar estão acontecendo de maneira frenética, principalmente no período de distanciamento social ocasionado pela pandemia do Corona Vírus Disease (COVID-19) e isso fez emergir novas necessidades formativas para o (a) professor (a) que encontrou nas Tecnologias de Informação e Comunicação (TIC), num universo em que se reconhece que a formação intelectual é apenas um componente a ser formado na escola e que ela não funciona independente do movimento que circula fora dela, mas está conectada, integrada e precisa atender a demandas cada vez mais dinâmicas.

Diante deste cenário, a formação continuada mostra-se como espaço de diálogo e reflexão entre professores e gestores, espaço em que há troca de experiências, dirimem-se dúvidas em que se colabora para o planejamento, para além da técnica e do pragmatismo, quando prevalece a dimensão emancipatória, que almeja a libertação e autonomia responsável (ALCOFORADO, 2014) para posicionar-se diante de situações apresentadas como imutáveis.

A urgência da formação continuada sentida no momento de retorno às aulas presenciais é um cenário distinto do vivido no período da pesquisa quando as atividades de formação continuadas, realizadas na escola para o coletivo dos professores, eram pouco comuns no ensino médio. Todavia, nas escolas pesquisadas, há registro de formações voltadas para a implantação do regime de tempo integral, ações de formação promovidas com recursos do Programa Ensino Médio Inovador (ProEMI) e do Pacto pelo Fortalecimento do Ensino Médio (PNFEM). 


\section{FORMAÇÃO NA ESCOLA: DIMENSÕES, ESPAÇOS, ORGANIZAÇÃO E VALORI- ZAÇÃO}

A primeira categoria de análise obtida a partir do corpus da investigação empírica, retrata a formação continuada de acordo com o discurso dos professores entrevistados. As evidências estão caracterizadas nas seguintes subcategorias: currículo e ambiente escolar; trabalho realizado em equipe; e desafios que exigem do professor maior engajamento. As contribuições dos professores estão destacadas em trechos considerados mais significativos no diálogo que se estabeleceu durante a pesquisa e estão dispostas a seguir:

\section{a) Currículo e ambiente escolar}

$\mathrm{Na}$ escola de tempo integral a palavra tempo assume um lugar de destaque. Com isto, o tempo da escola e o que é feito com ele em relação ao currículo e às relações no ambiente escolar são apresentados pelo(a)s professore(a)s como fator decisivo para que desenvolvam uma prática que eles mesmos definem como "eficiente", conforme verificamos nos discursos que se seguem.

A primeira contribuição, expressa a fala do(a) professor(a) BATERIA que relaciona a condição de professor à de educador, o que aprofunda e torna mais complexa a sua função, para além da condição de funcionário e complementa que tem a responsabilidade...

[...] com a formação humana em todas as dimensões [...] o conteúdo conceitual, procedimental e atitudinal, o que ensina não serve só para a prova, para o ENEM, mas para momentos sociais. [...] Educa para ser eficiente e eficaz. Nos projetos aprendem brincando, na ludicidade. (BATERIA - ENTREVISTA).

O (a) professor(a) BATERIA revela familiaridade com os princípios da educação integral, quando discorre sobre as múltiplas dimensões do humano e os conteúdos operacionalizados para a formação integral do educando e faz referência ao limite da matriz de referência do ENEM, ao tempo em que busca exemplificar como se efetivam os trabalhos com os diferentes tipos de conteúdo, quando afirma "o que ensina não serve só para o ENEM" (BATERIA - ENTREVISTA).

O discurso do(a) professor(a) BATERIA comunga com a orientação de uma prática pedagógica diversificada que acolha "[...] como ingredientes do ensino, essas aprendizagens de outras fontes, de outros mundos, de outras lógicas, para incorporá-las na qualidade de seu processo de ensino e na ampliação daquilo que se reputa necessário para o momento pedagógico do aluno" (FRANCO, 2016, p. 547).

A sintonia entre o discurso do(a) professor(a) BATERIA e a lógica desenvolvida por Franco (2016), mostra que a escola na prática deste(a) se faz reflexão e ação conforme preconizam Franco (2016) e Freire (2019). Nesse sentido, destacamos que a primeira e 
terceira parte de sua fala são impessoais, como se falassem de outro professor. Todavia, no segundo momento assume o comprometimento corresponsabilizado de sua prática pedagógica, quando usa o termo "acompanhamos".

O(a) Professor(a) BATERIA fala também da relação do estudante com a aprendizagem quando afirma. "aprendem brincando" e, ao mesmo tempo, revela que o processo de aprendizagem se faz de maneira agradável e prazerosa para o estudante.

A segunda contribuição faz referência aos projetos desenvolvidos na escola, segundo o (a) professor (a): "O projeto aproxima muito o professor do aluno. Expor para sociedade é um momento em que a gente se sente bem junto deles e também quando fazemos a for-mação para o ENEM, para os vestibulares" (VIOLÃO - ENTREVISTA). Com este discurso observamos a valorização dos projetos pedagógicos desenvolvidos na escola de maneira interdisciplinar, reconhecidos pelo(a) referido(a) professor(a) por promover a aproximação entre as categorias professor e aluno, o que é exemplificado quando relata sobre o senti- mento de bem-estar com a presença dos estudantes.

$\mathrm{O}$ (a) professor(a) VIOLÃO demarca a condição do professor como agente formador e, embora exemplifique uma formação específica preparatória para o ingresso no ensino superior, coloca a relevância do sentimento de bem-estar que, conforme afirma Imbernón (2016), a sala de aula é um espaço dinâmico que deve gerar afetividade, oportunidade para elevar a auto-estima do educando e permitir a democracia.

Neste contexto, os projetos pedagógicos são atividades interdisciplinares realizados como estratégia pedagógica para a promoção, experimentação e aplicação dos conhecimentos em eventos de culminância. Concorrem para o diálogo e com os estudantes, o que mostra um avanço em relação à ideia de juventude nas escolas de ensino médio de tempo integral, na perspectiva em que discutem Carrano e Dayrell (2013), evidenciada na expressão "a gente se sente bem junto deles". Vale considerar que um dos temas abordados na formação do Pacto pelo fortalecimento do Ensino médio foi justamente este.

Formada pela união das falas de dois professores (CAVAQUINHO e TROMPA), a terceira contribuição explica um pouco da rotina do estudante, a partir de três momentos distintos experienciados na escola,

Tem a parte curricular normal, Horário de Estudo e os Projetos trabalhados ao mesmo tempo. $\mathrm{O}$ aluno está sempre ocupado [...] a gente percebe o crescimento desses alunos no conhecimento e no comportamento. Participo de forma ativa, de tudo o que acontece dentro da escola, fico muito feliz" (CAVAQUINHO; TROMPA - ENTREVISTA).

O discurso identifica: 1- diferentes espaços de ensino-aprendizagem. 2- que o currículo formado pela base comum e diversificada como o Horário de estudo ${ }^{7}$ e os projetos, que

7 Horário destinado para realização de atividades feitas com a orientação de um professor. 
proporcionam a ocupação do estudante. Este trecho evidencia o que Tacca (2008) apresenta como sendo a sintonia do professor com o aluno, quando identifica sua motivação e emoções e expressa seu pensamento na conjunção de novas aprendizagens, fortalecendo o compromisso do professor com o educando.

O discurso dos professores é revelador do envolvimento destes na vida da escola, o que demonstra haver de fato diálogo entre professores e educandos e que a condição juvenil é respeitada.

Na quarta contribuição, a seguir, o discurso do(a) professor(a) CONCERTINA também é revelador quanto ao uso de diferentes espaços utilizados na escola, para as atividades pedagógicas. Observamos a preocupação com a criatividade dos estudantes e com o currículo desenvolvido com mais...

[...] tempo de trabalhar melhor esses conteúdos, principalmente os projetos, possibilidade de envolver o aluno de forma mais criativa. Às vezes ensaia até no horário de almoço, nos Horários de Estudo. Saio de sala de aula para fazer uma leitura de grupo no corredor ou na biblioteca, a gente se vê envolvido assim num projeto maior. Quando faço isso, dou oportunidade ao aluno de conseguir a melhor forma para mostrar que leu e entendeu o conteúdo (CONCERTINA - ENTREVISTA).

Para este(a) professor(a) o processo de ensino-aprendizagem não se restringe ao espaço da sala e o horário regulamentar da aula ganha outros contornos no interior da escola, o que envolve como espaços pedagógicos dos corredores à biblioteca. Estes espaços são utilizados em momentos nos quais as práticas educativas inovadoras produzem rupturas com o que Veiga (2003) denomina de organização do trabalho pedagógico fragmentado.

Os projetos e práticas desenvolvidos nestas escolas proporcionam maior liberdade de atuação dos professores, ou seja, o uso de estratégias diferenciadas com possibilidades para o diálogo, o que produz envolvimento e comprometimento dos envolvidos nestes processos (professores e estudantes).

Nesse sentido, a escola se faz mais dinâmica e reverbera o que afirma a contribuição do (a)professor(a) SAXOFONE, que expressa uma relação de confiança em que os estudantes.

[...] às vezes até no trabalho de nossos colegas pedem ajuda. O professor, só lança a ideia, os alunos são ativos, são dinâmicos, muito dedicados a esses trabalhos. [...] ou se enquadram nesse dinamismo, ou acabam desistindo, ou são reprovados. A gente consegue desenvolver um trabalho muito mais dinâmico. Esse tempo integral deveria ser mais visto pelas autoridades (SAXOFONE - ENTREVISTA).

Nesta última contribuição mesmo que implicitamente, encontramos a presença do trabaIho interdisciplinar favorecendo a educação integral na escola. Porém, este trecho é revelador em outro ponto que é nevrálgico no ensino médio, o abandono e a reprovação. O discurso em questão mostra que este é um problema também enfrentado nas escolas de tempo integral. 
As contribuições desta subcategoria demonstram a importância dos diferentes espaços e estratégias, como enriquecedores do currículo, que se configura como possibilidade na formação de protagonistas, possibilitada por uma visão holística e sistêmica que concorre à religação de saberes (MORIN, 2015).

Conforme os ditos, identificamos o ambiente escolar como espaço lúdico onde ocorre a interação como estratégia pedagógica em prol do ensino e da aprendizagem significativa, produzindo inovações nas relações entre professores e entre esses e com os estudantes.

b) Colaboração da Equipe

A segunda categoria evidencia que, entre o(a)s professore(a)s das escolas pesquisadas, predomina a solidariedade como articuladora do corpo docente, tanto nas atividades pedagógicas quanto nas de gestão geral de diferentes momentos da vida escolar e da sua importância para os resultados obtidos pelo grupo.

A cooperação está presente nos cinco trechos destacados, sendo que no primeiro discurso, o(a) professor(a) TROMBONE, exalta o prêmio de gestão conquistado pela escola e afirma que

A amizade, a solidariedade, o trabalho conjunto, em grupo. Temos momentos de angústias, de reflexões, de discussões, de medo, mas temos momentos de união para tentar resolver problemas diversificados. A gente já ganhou até um prêmio de melhor gestão. Me considero uma pessoa que participa da evolução da escola pública e de tempo integral que deu certo. (TROMBONE - ENTREVISTA).

Os termos amizade, solidariedade, equipe e união evidenciam que há diálogo entre o corpo docente. Na segunda parte do discurso encontramos referência a desafios para exemplificar sua superação com o engajamento da equipe. Com isto "[...] refere-se a algo além da prática didática, envolvendo: as circunstâncias da formação, os espaços-tempos escolares, as opções da organização do trabalho docente, as parcerias e expectativas do docente" (FRANCO, 2016, p. 542), ou seja, a prática pedagógica. Esta característica de trabalho coletivo também é evidenciada no segundo discurso:

[...] atividades de teatro, música, dança que vão contribuir para desenvolver o raciocínio do aluno, no processo de ensino e aprendizagem. Ajudamos na hora do almoço, os colegas, a direção e os alunos. Os que precisam, procuram os professores, aqui a gente se considera amigos deles, para sanar qualquer dúvida, ajudar no que for preciso (AGOGÔ - ENTREVISTA).

Nesse discurso o(a) professor(a) AGOGÔ exemplifica o trabalho interdisciplinar realizado na escola, que envolve teatro, música e dança, e apresenta outra forma de participação e envolvimento no cotidiano que extrapola a racionalidade pedagógica técnico-cien- 
tífica e se direciona à subjetividade do educando, que se estabelece em uma relação de interação defendida por Vigotsky (2010), que gera afetividade, partilha e confiança, fundamentais para a aprendizagem.

Os discursos em análise enfatizam a colaboração da comunidade escolar (gestores, professores e estudantes), como "[...] processo que pode ajudar a entender a complexidade do trabalho educativo e dar melhores respostas às situações problemáticas da prática" (IMBERNÓN, 2009, p. 60), a exemplo da participação de todos no momento do almoço, que também se faz processo de aprendizagem, ou os diversos espaços da escola, antes vistos apenas como espaços de passagem ou de lazer compreendidos como espaços de aprendizagem.

A lógica da colaboração, partilha e da complexidade do trabalho educativo, também se fazem presentes na contribuição seguinte:

Em todos os momentos, o professor participa dessa dinâmica: nos Horários de Estudo está tirando as dúvidas dos alunos. Cada professor tem Horário de Estudo em turmas diferentes. [...] Nosso currículo é diferenciado, além das disciplinas básicas, trabalhamos com oficinas, atividades diferenciadas, projetos interdisicplinares. Todo mundo se engaja, mesmo que não sejam áreas afins. Os alunos se sentem valorizados, quando todos estão assistindo (TIMBAL - ENTREVISTA).

O(a) professor(a) TIMBAL, pontua dois aspectos importantes das relações pessoais e profissionais, o primeiro ao situar o trabalho do Horário de Estudo, que além de reduzir a quantidade de atividade escolar que o estudante faz sem apoio, oportuniza ao professor acompanhar turmas diferentes, aproximando professor e estudante.

O segundo diz respeito ao trabalho interdisciplinar, que favorece engajamento de todos e o sentimento de valorização do estudante. Estes dois aspectos também são pontuados no discurso a seguir:

Têm aulas, Horários de Estudo onde ele (o estudante) escolhe a disciplina que quer estudar e tem a liberdade de procurar o professor, sentar e tirar dúvidas, estudar sozinho, em grupo. Sinto-me parte integrante, porque me dedico ao aluno em todos os momentos. Até na minha casa às vezes eles me procuram e na escola em todos os projetos estou inserida, buscando ajudar, seja um trabalho da direção, da coordenação, de outras disciplinas. A gente trabalha em conjunto e me sinto inserida em todo o trabalho da escola (HARPA - ENTREVISTA).

O trabalho coletivo engajado e a flexibilidade do currículo com o Horário de Estudo são as tônicas do trecho anterior, que apresenta textualmente o sentimento de pertencimento, presente nos discursos anteriores e no trecho seguinte do(a) professor(a) TROMBONE, que se apresenta emocionado(a) ao falar do trabalho realizado. 
[...] porque tem os Horários Pedagógicos Interdisciplinares (HPIs) que aproveitamos, buscando os pontos negativos que temos que melhorar, planejando juntos, elaborando as oficinas, buscando metodologias e práticas para estar melhorando o ensino e aprendizagem. Quando via as oficinas acontecendo, de música, de teatro, redação, os meninos de física fazendo maravilhas. É apaixonante! Isso acontece porque a escola de tempo integral proporciona isso. Dificuldades têm, mas tudo tem que ser direcionado, estudado e acima de tudo, trabalho de equipe, a integração, o respeito mútuo e com foco no resultado, a formação do aluno como protagonista da sua própria história (TROMPETE - ENTREVISTA).

Neste último trecho da subcategoria, o(a) professor(a) TROMPETE apresenta o Horário Pedagógico Interdisciplinar, como lugar de trabalho em que ocorre o planejamento dos projetos interdisciplinares e retoma os desafios frisados no primeiro discurso apresentado do(a) professor(a) TROMBONE e assim como ele, afirma que a integração da equipe é fator de superação.

Nesse sentido Placco e Souza (2008) deixam claro que qualquer prática educativa só evolui quando o trabalho é coletivo, o que para eles é fruto de integração da comunidade escolar, o que não é um processo natural, mas uma construção evidenciada pelos espaços específicos reservados aos encontros pedagógicos com os HPIs, entre outros e também pelas atividades de formação.

Diante do dito, afirmamos com base em Morin (2003) que os professores dessas escolas compreendem a complexidade do ato educativo e desenvolvem uma prática pedagógica que vai para além da sala de aula, trabalhando valores tais como a solidariedade, corresponsabilidade e amorosidade.

c) Tempo Integral: exigência, reconhecimento e qualificação

Na última categoria os professores evidenciam compromisso e angústia quanto ao trabalho realizado por ele(a)s na escola. Encontramos em todas as contribuições referência às exigências em relação ao professor e na primeira em destaque, nosso(a) colaborador(a) realça o dia a dia que leva ao desgaste:

Estou o dia todo ministando aulas, ajudando na gestão da escola. É muito puxado, muito sacrifício. Muitos não conseguem, vêm para o CEMTI, ficam um ano e saem, porque suga, puxa muito, a gente termina por não ter tempo nem para nossa família e para gente. Aqui no tempo integral, a gente trabalha tanto e não tem tempo nem para se qualificar, estudar. Não pensaram nisso (ÓRGÃO - ENTREVISTA).

A rotina é considerada desgastante, para o(a) professor(a), ÓRGÃO, sentimento expresso ao relatar que ministra aulas o dia todo e colabora com a gestão. Este discurso ilustra que, se de um lado encontramos compromisso, quando o(a) professor(a) além de suas aulas, contribui "ajundando na gestão da escola". é preocupação com outras dimensões da vida do professor, que são sacrificadas, como o tempo para cuidar da familia e de si. Situação que leva professores a deixarem a escola de tempo integral, segundo o relato exposto. 
Esta contribuição mostra que escola de tempo integral ao apresentar uma rotina de expansão da jornada para toda a comunidade escolar, o que difere da rotina da maioria das escolas, leva os professores a se comprometerem com uma nova dinâmica e mostra também a sensação de sacrifício, pela falta de tempo para se dedicarem a outras atividades durante a semana. O tempo da Escola é caracterizado pelo(a) professor(a) BANDOLIN ao informar sobre a rotina:

[...] nove horários de aula, aulas teóricas, de segunda a sexta, nove horários de aula, cada professor desempenha sua carga horária. Estou desde o início, venho desenvolvendo meu trabalho de forma benéfica, vesti realmente a camisa do tempo integral. Acho ideal a escola de tempo integral, um modo de ensinar bacana, exige demais do professor, devia ser mais reconhecida. Tira os alunos da rua, ficam mais focados no ensino (BANDOLIN - ENTREVISTA).

O(a) professor(a) BANDOLIN, ao expor sobre sua jornada de trabalho, mostra que valoriza a escola, mas também pontua que há muita exigência para o professor que trabaIha com a oferta de ensino em tempo integral, que considera não ser reconhecida como deveria. Nessa caso, a desvalorização do trabalho do professor a que se refere, está associada ao não reajuste no valor da gratificação (adicional ao salário, relativo à Dedicação Exclusiva) desde que as escolas foram criadas até o período da pesquisa, uma vez que os professores se mostram em outras falas contentes com o valor social que a comunidade em que a escola está localizada atribui à escola.

O discurso a seguir está relacionado à responsabilidade com a formação integral, na relação dialógica, afetiva e social:

A gente acolhe, dá um conforto, são alunos que vêm de escolas diferentes, de várias cidades do estado. Essa dinâmica exige muito do professor, não só uma preparação em termos de conhecimento da disciplina em sí, mas de vivência, de estar inserindo o aluno em um meio social. Não sou somente o professor de[...], mas o professor [...], me sinto presente e vejo o aluno como amigo, pode confiar em mim. Ele muitas vezes vai dizer: Professor, preciso conversar com o senhor e no final diz: Valeu professor! Obrigado! A gente sente que foi prazerosa, eficaz, houve uma interação, uma contribuição (TAMBOR - ENTREVISTA).

Neste trecho o(a) professor(a) TAMBOR, retoma a extensão do trabalho do(a) professor(a) que excede à atividade docente em sala de aula, o que, segundo o discurso, exige preparação mais ampla, que envolve afetividade, confiança, ou como afirma Freire (2019), exige comprometimento para estabelecer uma relação de diálogo. Está presente neste trecho, a responsabilidade com a educação integral, que envolve mais que a formação intelectual e que exige mais que a competência técnica do conteúdo a ser ensinado. 
O respeito pelo educando se configura no discurso do(a) professor(a) TAMBOR, ao mostrar que oportuniza a aprendizagem que transcende os conteúdos escolares, a partir de conversas e acolhimento que implicam afeto, orientação, conselhos, o que de fato, exige compromisso, empoderamento, reflexão sobre a ação (FRANCO, 2016).

A contribuição seguinte ressalta a pedagogia de projetos e o sentimento de bem-estar pelo trabalho realizado.

A partir do momento que entro, meu pensamento está voltado ao que fazer, além dos objetivos traçados no plano de aula, mas o que fazer para que sejam alcançados. Sou de trabalhar com projetos, tenho a Mostra e Gincana de Química, quando vejo aquilo que propomos ao aluno e ele mostrar melhor do que imaginamos, já é válido (TUBA - ENTREVISTA).

Nosso(a) colaborador(a) coloca em evidência a satisfação com o resultado do seu trabalho, pelo empenho dos alunos, que em sua avaliação apresenta-se em condição de Excelência. A preocupação com o planejamento é externada quando faz referência a estratégias para o alcance dos objetivos, à valorização dos projetos, o que é visto ao longo do texto como estratégia pedagógica adotada, inclusive para proporcionar o diálogo entre diferentes componentes curriculares.

No discurso do(a) professor(a) TUBA, a primeira parte é ilustrativa à imersão do(a) professor(a) em seu trabalho: "A partir do momento que entro, meu pensamento está voltado ao que fazer [...]", o que indica dedicação e engajamento, para desenvolver uma prática pedagógica conforme orienta o artigo 26 das Diretrizes Curriculares Nacionais da Educação, de considerar na proposta pedagógica os sujeitos envolvidos no processo ensino-aprendizagem "[...] como sujeitos históricos e de direitos, participantes ativos e protagonistas na sua diversidade e singularidade" (CONSELHO NACIONAL DE EDUCAÇÃO, 2018), o que exige maior dedicação do professor, considerando a perspectiva de educação puramente intelectual, própria de uma concepção de educação mais conservadora.

Em todos os discursos destacados, encontramos elementos que se complementam, demonstrando a dedicação do corpo docente com sua prática pedagógica, o entusiasmo de TUBA e TAMBOR com suas experiências e relacionamentos interpessoais na escola, a angústia e preocução com as exigências requeridas para o exercício docente, presentes no discurso de BANDOLIN e ÓRGÃO, e a necessidade de formação costatada pelo(a) professor(a) ÓRGÃO, tema da próxima categoria analisada.

\section{EXPERIÊNCIA DE FORMAÇÃO: FORTALECIMENTO DA PROFISSIONALIDADE DOCENTE E INCENTIVO A (AUTO)FORMAÇÃO}

Nesta quarta seção, a categoria trabalhada apresenta a ideia central de que as reflexões teóricas sobre a prática pedagógica e a aprendizagem fortalecem a profissiona- 
lidade docente. Nesta destacam-se as contribuições de professore(a)s que rememoram seus processos formativos e as implicações em suas práticas. São três subcategorias complementares.

a) Evolução intelectual e desenvolvimento de estratégias

São quatro contribuições nesta subcategoria, começamos nossa análise com o(a) professor(a) HARPA que destaca:

\begin{abstract}
Antes eu pegava o livro, selecionava o conteúdo, fazia os exercícios e não tinha visão de que o aluno não vai sozinho ligar a teoria à prática, às coisas da vida. Depois desses cursos trago meus alunos para aplicar na vida o que eles aprenderam em sala de aula[...]. Os avanços, a gente nota a cada dia, quando o aluno entra tem uma visão e ela vai se ampliando e quando no final do ano tem pouquíssimas reprovações. (HARPA - ENTREVISTA).
\end{abstract}

HARPA de maneira clara e objetiva relata o significado da formação continuada no seu desenvolvimento profissional, e mostra o resultado na aprendizagem dos estudantes, que para ele(a), reflete nas aprovações. Expressou que houve mudança em seu modo de se relacionar com o conhecimento pedagógico e com o exercicio docente.

A aprendizagem do estudante é elemento destacado nos discursos do(a)s professore(a)s AGOGÔ e TROMBONE, conforme se verifica na primeira parte do discurso a seguir:

[...] juntar colegas de trabalho, desenvolver projetos, estratégias específicas para contribuir com a aprendizagem do aluno e fazer com que goste de ficar na escola, tornar a vida deles mais agradável. Quando a gente faz determinado curso, passa a conhecer melhor certas questões, tem uma evolução intelectual e passa a ter mais maturidade para resolver e aceitar certos problemas que acontecem na escola, podemos colocar nossos pontos de vista, ver a opinião dos colegas e chegar à conclusão que às vezes, falta um pequeno detalhe para que o nosso desempenho seja melhor. Tem uma grande melhora no índice de desenvolvimento, envolvemos melhor os alunos (AGOGÔ; TROMBONE - ENTREVISTA).

AGOGÔ e TROMBONE colocam em seus discursos a evolução intelectual e a maturidade para resolver problemas de cunho pedagógico, o que passa pela experiência que resulta da vivência refletida, como é dito expressamente, "melhora no índice de desenvolvimento" (AGOGÔ; TROMBONE - ENTREVISTA). Todavia a próxima contibuição coloca a insuficiência dos momentos de atividades formais de formação, conforme verificamos:

São insuficientes os momentos de formação continuada para a escola e o processo educativo atual. Deveria ter mais oportunidades, mas são válidos. É o momento 
em que a gente vai questionar nossa prática e buscar formas para melhorar, fazer uma avaliação da prática, rever a forma como os conteúdos devem ser trabalhados. (CONCERTINA - ENTREVISTA).

O(a) professor(a) CONCERTINA afirma que, embora sejam poucas as atividades de formação no período, são válidas e justifica que nestes momentos se faz o questionamento em relação à prática, revê a forma de se trabalhar o conteúdo, ou seja, o trabalho pedagógico em si, a análise positiva sobre as atividades formativas. Porém, não são unânimes, verificamos no discurso a seguir, uma perspectiva diferente.

\begin{abstract}
A gente praticamente tem aprendido sozinho, na prática. Porque foi muito superficial quando a gente teve essa formação. Ao longo desse tempo que foi implantado o ensino integral, deveria ter tido mais formações. O professor tem que estar se reinventando a cada dia, principalmente porque nós trabalhamos com o ser humano e ele muda constantemente. Sempre que posso, independente de serem temas repetitivos, participo porque só vem a acrescentar na minha prática. (TIMBAL - ENTREVISTA).
\end{abstract}

O(a) professor(a) TIMBAL, em seu discurso concebe as formações das quais participou como superficiais, segundo ele(a) na escola de tempo integral deveria ter havido mais atividades formativas formais, mostrando já na primeira parte de sua fala a falta que sente da formação e na última parte afirma que, mesmo sendo "superficiais", não desistiu e coloca a sua importância, "independente de serem temas repetitivos, participo porque só vem a acrescentar na minha prática” (TIMBAL - ENTREVISTA).

De modo geral os discurso dos quatro colaboradores revelam que estes reconhecem a relevância da formação continuada para o desenvolvimento profissional. Todavia, a experiência da formação continuada na escola, nem todos a concebem como tendo contribuido de fato para sua prática, a exemplo do discurso do(a) professor(a) TIMBAL.

Para estes professores, a formação continuada apresenta-se como oportunidade de reflexão sobre sua prática, inovação em estratégias e contribuição para o processo de aprendizagem do educando, o que corrobora com a ideia de que o "[...] fazer pedagógico constitui-se em orientação, mediação, facilitação construídas na conexão entre sujeitos e sua condição material de existência" (MOURA; MOURA, 2021, p.146).

Nesse sentido as atividades de formação continuada são possibilidades de ampliação do conhecimento pedagógico com o aperfeiçoamento de estratégias de ensino, avaliação para que a aprendizagem do(a) estudante seja mais significativa. Esta é a conexão que é feita com a segunda categoria analisada a seguir.

b) Reflexão teórico-prática: mudança de postura

Nesta subcategoria as contribuições foram divididas em cinco segmentos de textos, que mostram que nas atividades formativas os professores percebem a conexão teoria-prática, que, perceptível ou não, está sempre presente no trabalho realizado na escola. A 
primeira contribuição de BATERIA que apresenta esta relação no primeiro trecho do seu discurso, conforme, está descrito adiante:

Ajudam a refletir sobre nossa prática na sala de aula. Nas faculdades, temos uma formação puramente academicista, é ensinado a ensinar conteúdo e não formar gente. Esses cursos oferecem instrumentos, momentos de reflexão, elementos e técnicas que favorecem nossas práticas. Tão logo iniciei, era muito conteudista, gramatiqueiro. (BATERIA - ENTREVISTA).

No discurso anterior, o(a) professor(a) BATERIA expressa a ruptura exposta no discurso do(a) professor(a) HARPA, o que configura o entrelaçamento das diferentes subcategorias, em relação ao significado da formação continuada e que convergem para a prática docente, no sentido da mudança de postura realçada no discurso seguinte.

[...] Contribuiu bastante para mudar nossa postura em relação à escola e o que hoje a gente trabalha com o tempo integral. A própria prática pedagógica de sala de aula, a dinâmica de sala de aula mudou, você passa a analisar. Será que estou fazendo a coisa certa? O resultado é mais satisfatório, o aluno tem uma participação mais ativa, são mais dedicados (CAVAQUINHO; VIOLÃO - ENTREVISTA).

A contibuição do(a)s professore(a)s CAVAQUINHO e VIOLÃO, evidencia a necessidade da mudança em relação ao que se propõe ao tipo de escola na qual estão trabalhando (de tempo integral), mostra que se questiona a ação exercida e sua experiência e conclui que tem resultado, participação ativa e dedicação dos estudantes. O que se espera de uma escola que tem como um dos objetivos o desenvolvimento o protagonismo (PIAUÍ, 2008).

A formação continuada abre caminho para outras possibilidades, me faz ver coisas que eu podia desenvolver na minha disciplina. Didaticamente falando, percebo os erros que estou cometendo na hora da aula, como posso modificar e fazer o planejamento. Há também a troca de experiências com os parceiros. Possibilitou avanços porque a forma como foi repassado para nós, os cursos de formação, tinham muito haver com o dia a dia da nossa prática dentro de sala de aula. Eram atividades que realmente abordavam as necessidades que a gente tinha em sala. Atendeu nossas necessidades (BANDOLIN - ENTREVISTA).

O(a) professor(a) BANDOLIN concebe a formação continuada como oportunidade de desenvolvimento por propocionar troca de experiências, reflexão, planejamento. Fala de necessidades, o que a articula com o discurso que o antecedeu. Esta contribuição, poderia também estar disposta neste texto, como posterior à proxima, mas optamos por esta sequência justamente para que seja considerado o impacto causado no(a) professor(a) SAXOFONE a primeira formação realizada para a implantação do regime de tempo integral. Vejamos: 
A primeira formação do tempo integral foi essencial. Eu acho que se a gente não tivesse tido essa formação a situação poderia ser pior, mais dramática. Acredito que a gente acertou mais do que errou. Cada formação dessas é bem vinda, é necessária. Teve um curso, sobre currículo do tempo integral e a gente viu a dinâmica de outras escolas que já tem anos de tempo integral. $\mathrm{O}$ tempo integral era uma novidade na cidade, no estado[...] (SAXOFONE - ENTREVISTA).

SAXOFONE nos remete à reflexão sobre a condição do(a) professor(a) diante do novo, o regime de tempo integral, "uma novidade", receio de não dar certo, "a situação poderia ser pior, mais dramática", um desafio que, segundo o professor, foi vencido "a gente acertou mais do que errou". Entendida dessa forma, a formação continuada na escola de tempo integral incetiva a reflexão real dos sujeitos sobre sua prática, fazendo-se formação permanente (IMBERNÓN, 2016). Todavia, chama atenção o discurso a seguir que retrata a dificuldade de intervenção, quanto a questões que possam não convergir com a orientação do sistema de ensino.

Alguns sim, outros a gente se sente até um pouco revoltada por bater numa mesma tecla, por conta do Sistema a gente não tem uma abertura para tomar decisões (TUBA - ENTREVISTA).

Para o(a) professor(a) as tentativas de fazer alterações mais efetivas em relação às atividades desenvolvidas na escola esbarram em empecílhos que, segundo ele(a), não permite tomar decisões. A reflexão supracitada mostra, embates entre propostas advindas de atividades formativas em conflito com o que está posto pelo sistema escolar, uma construção que remete a Nóvoa (2019), ao refletir sobre as mudanças no contexto escolar e que seguramente transformam profundamente a profissão docente à formação de professores.

Nesse contexto que reflete mudanças, o(a)s colaboradores em sua maioria concordam que a formação continuada na escola vem contribuindo como subsídio para alterar a postura em relação ao conteúdo, ao estudante, ao colega que repercute na prática docente, o que implica na dimensão colaborativa, apontada por Imbernón (2016). Situação ilustrada pelo(a)s colaboradore(a)s, quando remetem ao resultado na aprendizagem do estudante, questão central discutida a seguir.

\section{c) Aprendizagem do aluno}

O objetivo da formação continuada é o aperfeiçoamento. Na escola esta formação ganha contornos ainda mais significativos em relação ao coletivo, ao trabalho colaborativo com vistas à finalidade do fazer pedagógico, a razão e existir da própria escola. Nesse sentido, nas contribuições desta última subcategoria, agrupadas em quatro segmentos, temos a expressão ORGÃO e TROMPETE que avaliam um dos cursos, 
[...] oportunidade de falar das nossas experiências, redirecionar nossos planos de aula. Em sala de aula vem evoluindo como trabalhar de forma interdisciplinar e até transdisciplinarmente [...] Possibilitaram avanços, mas poderia melhorar se a gente voltasse a nossa realidade. O Pacto é porque foi oferecido no chão da escola (ÓRGÃO; TROMPA - ENTREVISTA).

Discorrem sobre o Pacto pelo Fortalecimento do Ensino Médio e relatam a importância da troca de experiências, no processo de construção de um novo modo de trabalhar, a "forma interdisciplinar e até transdisciplinarmente", aprendedo num ambiente colaborativo (IMBERNÓN, 2009). O destaque, todavia é o resultado do processo, que não é estático, pois com ele um outro processo se constrói de ensino-aprendizagem, exemplificado nos dois discursos seguintes.

Temos um projeto que foi elaborado na formação, para ser executado na prática. A culminância desse curso, foi anexado na Proposta Pedagógica direcionada à escola de tempo integral. [...] Tivemos avanços na nossa avaliação externa do SAEPI que estava abaixo do básico, a medalha de prata nas olimpíadas de matemática, de bronze na olimpíada internacional. Nossos alunos participaram da Gincana Cultural de História. Tivemos TV registrando nossas oficinas, fizemos viagens, passeios didáticos, utilizando recursos do PROEMI (TROMPETE - ENTREVISTA).

[...] As próprias estatísticas da escola mostram que a sociedade aceitou bem a escola de tempo integral. Ela é bastante procurada, já aprovou grande quantidade de pessoas para entrar na universidade, é procurada pela qualidade (VIOLÃO - ENTREVISTA).

O(a)s professore(a)s TROMPETE e VIOLÃO identificam em seus discursos como percebem a evolução do seu trabalho no resultado que a escola obtém junto à sociedade e às atividades das quais participa no sistema educacional. Neste sentido, corrobora Imbernón (2016), quando o autor avalia que o professorado e sua formação compreendida como formação permanente são imprescindíveis para que a educação tenha qualidade. Uma avaliação mais completa a este respeito é feita no próximo discurso:

Possibilitou várias reflexões sobre nossa prática pedagógica e a gente se comoveu, amadureceu como ser humano, possibilitou avanços. A escola está se classificando bem nas atividades que se envolve e isso é resultado de profundas reflexões que aconteceram. Resultados em números, de forma não só qualitativa, mas também quantitativa em relação ao serviço que presta à comunidade (TAMBOR - ENTREVISTA).

O(a) professor(a) TAMBOR evidencia a necessária relação qualidade-quantidade, para identificarmos os avanços obtidos na escola pública, pois a subjetividade é a matéria prima do nosso trabalho, mas ela se materializa na permanência do(a) estudante, na sua 
aprovação, no seu desempenho em torneios, gincanas, feiras de ciências, na participação das atividades da escola.

O que verificamos na síntese das contribuições que compuseram esta subcategoria, é ampliada para toda a categoria, pois as reflexões sobre a prática pedagógica, oportunizaram mudanças na docência, nas relações entre professore(a)s e entre e os estudantes, refletindo-se no processo ensino-aprendizagem.

Ante o exposto, corroboramos a ideia de que a formação continuada na escola é espaço singular que colabora com a configuração de uma nova construção pedagógica em que os professores refletem e trabalham coletivamente (NÓVOA, 2019), o que contribui para o fortalecimento da profissionalidade docente, uma vez que amplia as relações profissionais e fortalece a identidade profissional. Assim, o lócus da pesquisa - a escola de tempo integral, que trouxe a emergência da formação a este(a)s professore(a)s, é ela própria resultado das mudanças em curso.

\section{CONCLUSÃO}

A formação continuada de professores na perspectiva da educação permanente é um conceito em processo de construção na escola de educação básica, inclusive, do ensino médio, que funciona em regime tempo de integral, principalmente em função de sua especificidade e garantia da qualidade de ensino, com vistas à formação integral do estudante.

Neste sentido, a pesquisa evidenciou que o(a)s professore(a)s concebem a organização da escola com as atividades curriculares nos horários de aula e no horário de estudos, que tem como finalidade a formação das diferentes dimensões do educando e princípios da educação integral.

Assim, a rotina das escolas pesquisadas, fortemente marcada pela expansão da jornada escolar, é apontada como propícia ao desenvolvimento de práticas pedagógicas inovadoras, capazes de promover a compreensão dos conteúdos a partir da associação entre teoria e prática, com o desenvolvimento de atividades de vivência e reflexão, como estratégia docente e como prática formativa dos próprio(a)s professore(a)s.

Verificamos que o(a)s professore(a)s pesquisado(a)s organizam arranjos pedagógicos diferenciados em função da adoção da pedagogia de projetos, na qual desenvolvem atividades interdisciplinares voltadas para as necessidades de aprendizagem e da realidade local. Além das atividades de preparação, realizadas em espaços mais restritos, como a sala de aula, promovem sua culminância em eventos como feiras, festivais, saraus, que ocupam a escola toda e até praças e teatros.

Pela dimensão que tomam estas atividades, afirmamos que nestas escolas as práticas pedagógicas são pautadas, principalmente, na colaboração mútua entre professores e que estes demonstram em seus discursos que esta prática interdisciplinar e solidária, 
resulta de atividades de formação, o que denota a relevância da formação na escola para o desenvolvimento da profissionalidade docente.

Evidenciamos, outrossim, sua contribuição para a aquisição de conhecimentos pedagógicos, mudanças nas práticas e nas relações. No entanto, verificamos que a cultura de formação ainda não estava estabelecida no período da realização da pesquisa, uma vez que tivemos relatos de "insuficiência". Outra crítica, foi relativa à superficialidade das formações. E, por isto, sugerimos que estes dois pontos sejam considerados no planejamento de atividades de formação continuada de escolas e Redes de Ensino.

Em síntese, constatamos que a formação continuada na escola é uma necessidade em meio a uma realidade permeada por mudanças. Diante deste cenário, ela representa tanto a oportunidade de conhecer perspectivas e experiências diferentes, quanto de novos conhecimentos. Alertamos, todavia, que esta formação, para ser significativa, deve estabelecer sempre o diálogo entre teoria e prática. 


\section{REFERÊNCIAS}

ALCOFORADO, Luís. Desenvolvimento profissional, Profissionalidade e Formação Continuada de professores: possíveis contributos dos relatos autobiográficos profissionais. Revista Educação UFSM. v. 39, n.1, jan./abr, 2014. Disponível em: https://periodicos.ufsm.br/reveducacao/article/ view/11343. Acesso em: 22 jul. 2020.

CARRANO, Paulo; DAYRELL, Juarez (Org.). Formação de professores de ensino médio, etapa I: o jovem como sujeito do ensino médio. Curitiba: UFPR, 2013.

FRANCO, Maria Amélia do Rosário Santoro. Prática pedagógica e docência: um olhar a partir da epistemologia do conceito. Revista Brasileira de Estudos Pedagógicos. (on-line), Brasília, v. 97 , n. 247, p. 534-551, set./dez. 2016. Disponível em: https://doi.org/10.1590/s2176-6681/288236353. Acesso em: 24 ago. 2020.

FREIRE, Paulo. Pedagogia da Autonomia: saberes necessários à prática educativa. 58 ed. Rio de Janeiro/São Paulo: Paz e Terra, 2019.

IMBERNÓN. Francisco. Formação Permanente do Professorado. São Paulo: Cortez, 2009.

IMBERNÓN. Francisco. Qualidade do Ensino e Formação do Professorado: uma mudança necessária. São Paulo: Cortez, 2016.

MINISTÉRIO DA EDUCAÇÃO. Secretaria de Educação Básica/Coordenação Geral de Ensino Médio. 2009.

MOURA, Marcoelis Pessoa de; MOURA, Maria da Gloria Carvalho. MOURA, Reflexão sobre a aprendizagem de pessoas jovens e adultas: diálogo entre as teorias críticas e a andragogia. $\mathbf{R e}-$ vista Educação e Emancipação. São Luís, v. 14, n. 2, mai/ago. 2021. Disponível em: http://dx.doi. org/10.18764/2358-4319.v14n2p131-158. Acesso: 10 nov. 2021.

MORIN, Edgar. A Cabeça Bem Feita: repensar a reforma, reformar o pensamento. 8 ed. Rio de Janeiro: Bertrand Brasil, 2003.

MORIN, Edgar. Os sete saberes necessários à educação do futuro. 2 ed. São Paulo: Cortez, 2011.

MORIN, Edgar. A Via: para o futuro da humanidade. 2 ed. Rio de Janeiro: Bertand Brasil, 2015.

NÓVOA, António. Prefácio. In: JOSSO, Marie-Christine. Experiências de Vida e Formação. São Paulo: Cortez, 2004. p. 11-17.

NÓVOA, António. Os Professores e a sua Formação num Tempo de Metamorfose da Escola. Educação e Realidade, Porto Alegre, v. 44, n. 3, 2019, p. 1-15. Disponível em: Educação \& Realidade (ufrgs.br) Acesso em: 10 de out. 2021.

ORLANDI, Eni Puccinelli. Análise de Discurso: princípios e procedimentos. São Paulo: Pontes, 1988. 
ORLANDI, Eni Puccinelli. Discurso em Análise: sujeito, sentido, ideologia. Campinas, SP: Pontes Editores, 2012.

PIAUÍ. Decreto $\mathrm{n}^{\circ}$ 13.457, de 18 de dezembro de 2008. Institui no âmbito da Secretaria de Estado da Educação os Centros Estaduais de Tempo Integral. Diário Oficial do Estado n. 242,. Teresina, PI, Imprensa Oficial, 2008 p. 04. Disponível em: http://www.diariooficial.pi.gov.br . Acesso em: 05 jan. 2020.

PIAUÍ. Lei n 7.113, de 27 abril de 2018. Institui no âmbito da Secretaria de Estado da Educação os Centros Estaduais de Tempo Integral - CETIs, e dá outras providências. Diário Oficial do Estado do Piauí. n.79, Imprensa Oficial, 2018, p. 1-2. Disponível em: http://www.diariooficial.pi.gov.br. Acesso em: 05 jan. 2020.

PLACCO, Vera Maria Nigro de Souza; SOUZA, Vera Lúcia Trevisan. Desafios ao coordenador pedagógico no trabalho coletivo da escola: intervenção ou prevenção? In: PLACCO, Vera Maria Nigro de Souza ALMEIDA, Laurinda Ramalho de. O coordenador pedagógico e os desafios da educação. São Paulo: Edições Loyola, 2008. p. 25 - 36.

REIS, Juliana Batista dos; DAYRELL, Juarez. Experiências juvenis contemporâneas: reflexões teóricas e metodológicas sobre socialização e individualização. Revista Educação -UFSM. Santa Maria, v. 45, 2020. Disponível em: https://periodicos.ufsm.br/reveducacao 2020. Acesso em: 02 mai. 2021.

ROCHA, Raquel Barbosa; ARRUDA, Marina Patrício de; ANDRADE, Izabel Cristina Feijó de. FORMAÇÃO DE PROFESSORES EM SERVIÇO: narrativas de produção de si e do mundo. Cadernos de Pesquisa, São Luís, v. 25, n. 1, jan./mar. 2018, p. 95-108. Disponível em: http://www.periodicoseletronicos.ufma.br. Acesso em: 02 mai. 2021.

SILVA, Mônica Ribeiro da. O Programa Ensino Médio Inovador como Política de Indução a Mudanças Curriculares: da proposta enunciada a experiências relatada. Educação em Revista. Belo Horizonte, v.32, n.02, Abr./jun, 2016. p.91-110. Disponível em: http://dx.doi.org/10.1590/0102-4698153170. Acesso em: 02 mai. 2021.

TACCA, Maria Carmem V.R.. Estratégias Pedagógicas: conceituação e desdobramentos com foco nas relações professor-aluno. In: TACCA, Maria Carmem V.R. (org.). Aprendizagem e trabalho pedagógico. 2. ed. Campinas, SP: Editora Alínea, 2008.

VEIGA, IIma Passos Alencastro. Inovações e Projeto Político-pedagógico: uma relação regulatória ou emancipatória? Caderno Cedes, Campinas, v. 23, n. 61, p. 267-281, dez. 2003 Disponível em: http://www.cedes.unicamp.br. Acesso em: 22 jul 2019.

VIGOTSKY, Lev Semenovich. Aprendizagem e desenvolvimento intelectual na idade escolar In: VIGOTSKI, Lev Semenovich; LURIA, Alexander Romanovich; LEONTIEV. Alex Nikolaevich. Linguagem, Desenvolvimento e Aprendizagem. 11. ed. Tradução de: Maria da Pena Villalobos. São Paulo: Ícone, 2010.

YIN. Robert K. Estudo de caso: planejamento e métodos. 4. ed. Porto Alegre: Bookman, 2010. 